Nat. Hazards Earth Syst. Sci., 18, 2921-2932, 2018

https://doi.org/10.5194/nhess-18-2921-2018

(C) Author(s) 2018. This work is distributed under

the Creative Commons Attribution 4.0 License.

\title{
Risk zoning of typhoon disasters in Zhejiang Province, China
}

\author{
Yi Lu ${ }^{1}$, Fumin Ren ${ }^{2}$, and Weijun $\mathrm{Zhu}^{3}$ \\ ${ }^{1}$ Shanghai Typhoon Institute of China Meteorological Administration, Shanghai 200030, China \\ ${ }^{2}$ State Key Laboratory of severe weather; Chinese Academy of Meteorological Sciences, Beijing 100081, China \\ ${ }^{3}$ Key Laboratory of Meteorological Disaster of Ministry of Education, Nanjing University of Information, \\ Science \& Technology, Nanjing 210044, China
}

Correspondence: Fumin Ren (fmren@163.com)

Received: 18 January 2018 - Discussion started: 23 February 2018

Revised: 22 October 2018 - Accepted: 25 October 2018 - Published: 8 November 2018

\begin{abstract}
In this paper, typhoon simply means tropical cyclone. As risk is future probability of hazard events, when estimated future probability is the same as historical probability for a specific period, we can understand risk by learning from past events. Based on precipitation and wind data over the mainland of China during 1980-2014 and disaster and social data at the county level in Zhejiang Province from 2004 to 2012, a study on risk zoning of typhoon disasters (typhoon disasters in this paper refer to affected population or direct economic losses caused by typhoons in Zhejiang Province) is carried out. Firstly, characteristics of typhoon disasters and factors causing typhoon disasters are analyzed. Secondly, an intensity index of factors causing typhoon disasters and a population vulnerability index are developed. Thirdly, combining the two indexes, a comprehensive risk index for typhoon disasters is obtained and used to zone areas of risk. The above analyses show that southeastern Zhejiang is the area most affected by typhoon disasters. The annual probability of the occurrence of typhoon rainstorms $>50 \mathrm{~mm}$ decreases from the southeast coast to inland areas, with a maximum in the boundary region between Fujian and Zhejiang, which has the highest risk of rainstorms. Southeastern Zhejiang and the boundary region between Zhejiang and Fujian provinces and the Hangzhou Bay area are most frequently affected by extreme typhoon winds and have the highest risk of wind damage. The population of southwestern Zhejiang is the most vulnerable to typhoons as a result of the relatively undeveloped economy, mountainous terrain and the high risk of geological disasters in this region. Vulnerability is lower in the cities due to better disaster prevention and reduction strategies and a more highly educated population. The southeast coastal areas face the highest risk of typhoon disasters,
\end{abstract}

especially in the boundary region between Taizhou and Wenzhou cities. Although the inland mountainous areas are not directly affected by typhoons, they are in the medium-risk category for vulnerability.

\section{Introduction}

Typhoon, which means tropical cyclone in this paper, often causes some of the most serious natural disasters in China, with an average annual direct economic loss of about USD 9 billion. The arrival of a typhoon is often accompanied by heavy rain, high winds and storm surges, with the main impacts in southern coastal areas of China (Zhang et al., 2009). Zhejiang Province is seriously affected by typhoons - for example, in 2006, super-typhoon Sang Mei caused 153 deaths in Cangnan County in Wenzhou City, with CNY 11.25 billion of direct economic losses. Therefore it would be of practical significance to develop a system for the risk assessment of typhoon disasters in Zhejiang Province.

Major risk assessment models include the disaster risk index system of the United Nations Development Program (global scale, focusing on human vulnerability), the European multiple risk assessment (with emphasis on factors causing disasters and vulnerability) and the American Hazus$\mathrm{MH}$ hurricane module and disaster risk management system. Vickery et al. (2009), Fang and Shi (2012), and Fang and Lin (2013) reviewed the factors causing typhoon disasters. Rain and wind are direct causes of typhoon disasters (Emanuel, 1988, 1992, 1995; Holland, 1997; Kunreuther and Roth, 1998); stronger typhoons produce heavier rain and stronger winds, resulting in a greater number of casualties 
and higher economic losses. Many of the studies on the factors causing typhoon disasters used a grade index and the probability of occurrence (H. Y. Chen et al., 2011; Su et al., 2008; Ding and Shi, 2002; Chen, 2007). Recently, some studies built quantitative assessments in some provinces and carried out preliminary studies on pre-evaluating typhoon disasters (Huang and Wang, 2015; Yin and Li, 2017).

In terms of vulnerability, Pielke and Landsea (1998) and Pielke et al. (2008) combined the characteristics of typhoons and socioeconomic factors, suggesting that both the vulnerability of the population and economic factors were important in estimating disaster losses. The vulnerability of a population is a preexisting condition that influences its ability to face typhoon disasters. Among the most widely used indexes is the Social Vulnerability Index (SoVI) (Cutter et al., 2003; W. F. Chen et al., 2011). Other researches have focused on the vulnerability of buildings, obtaining a fragility curve by combining historical loss with the characteristics of buildings and typhoons (Hendrick and Friedman, 1966; Howard et al., 1972; Friedman, 1984; Kafali and Jain, 2009; Pita et al., 2014). Studies in China have assessed vulnerabilities to typhoon disasters (Yin et al., 2010; Niu et al., 2011). Evaluation indexes for the assessment of disaster losses were established based on the number of deaths, direct economic losses, the area of crops affected and the number of collapsed houses. These indexes were used to construct different disaster assessment models (Liang and Fan, 1999; Lei et al., 2009; Wang et al., 2010). Xu et al. (2015) comprehensively assessed the impact of typhoons across China using the geographical information system. The future direction of tropical cyclone risk management is quantitative risk models (Chen et al., 2017).

Previous studies have concentrated on semiquantitative large-scale research, with less emphasis on quantitative research at the county level based on large numbers of accurate data. In addition, the studies have paid more attention to disaster losses. Few studies have focused on a comprehensive risk assessment of typhoon disasters coupled with factors causing typhoon disasters and population vulnerability. In this study, Zhejiang Province, which is frequently affected by the strongest landfall typhoons (Ren et al., 2008) and experiences most serious typhoon disasters (Liu and $\mathrm{Gu}, 2002$ ) on the mainland of China, is selected as the study area. This paper does not consider the impact of storm surges. The factors causing typhoon disasters are represented by typhoon rain and typhoon wind. Section 2 introduces the data and methods used in this study. Section 3 provides analyses on typhoon disaster losses and factors causing typhoons. Section 4 presents risk assessment and regionalization of typhoon disasters. Summary and discussions are given in the final section.

\section{Data and methods}

This study is carried out in Zhejiang Province (Fig. 1) including 11 cities along the Yangtze River Delta. Zhejiang Province borders the eastern part of the East China Sea, is adjacent to Fujian Province, and is one of the most economically powerful provinces in China.

\subsection{Data}

\subsubsection{Typhoon, precipitation and wind data}

The typhoon data used in this study are the best-track tropical cyclone datasets from the Shanghai Typhoon Institute for the time period 1960-2014 (Eunjeong and Ying, 2009; Li and Hong, 2015). Daily precipitation data for 2479 stations and daily wind data for 2419 stations during the time period 1960-2014 over the mainland of China are obtained from the National Meteorological Information Center. The maximum wind speed is given as the maximum 10 min mean. In this paper, two time periods of precipitation and wind data are used.

Because of limited access to county-level typhoon disaster data, we have only obtained data from 2004 to 2012. So when calculating intensity index of factors causing typhoon disasters, the time period of typhoon precipitation and typhoon wind is the same as for the typhoon disasters and is 2004 2012.

For risk analyses of typhoon precipitation and typhoon wind (please see details in Sect. 3.1 and 3.2), estimated future probability is the same as historical probability, and we then select the period of 1980-2014. As Lu et al. (2016) mentioned, considering the homogeneity of wind data, we use the period of 1980-2014 for wind analysis. To ensure the consistency between wind and precipitation data, 1980-2014 is selected as the period. In addition, the objective synoptic analysis technique (OSAT) is needed to identify typhoon wind and precipitation from a wider range than just Zhejiang Province (please see details in Sect. 2.2.1); thus 2419 stations of precipitation data and 2479 stations of wind data over mainland China are used, 71 stations of which correspond to counties in Zhejiang Province.

\subsubsection{Disaster and social data}

Disaster data for each typhoon that affected Zhejiang Province from 2004 to 2012 are obtained from the National Climate Center and the number of records for each county is shown in Fig. 2. Of the 11 cities in Zhejiang Province, Wenzhou and Taizhou record the most typhoon disasters, with the maximum being 17 at Wenzhou. Fewer typhoon disasters are recorded in the central and western regions of Zhejiang Province, particularly in Changshan and Quzhou, which may be because the strength of typhoons weakened after landfall. The population data in 2010 are obtained from the sixth national population census (Population Census Office of the 


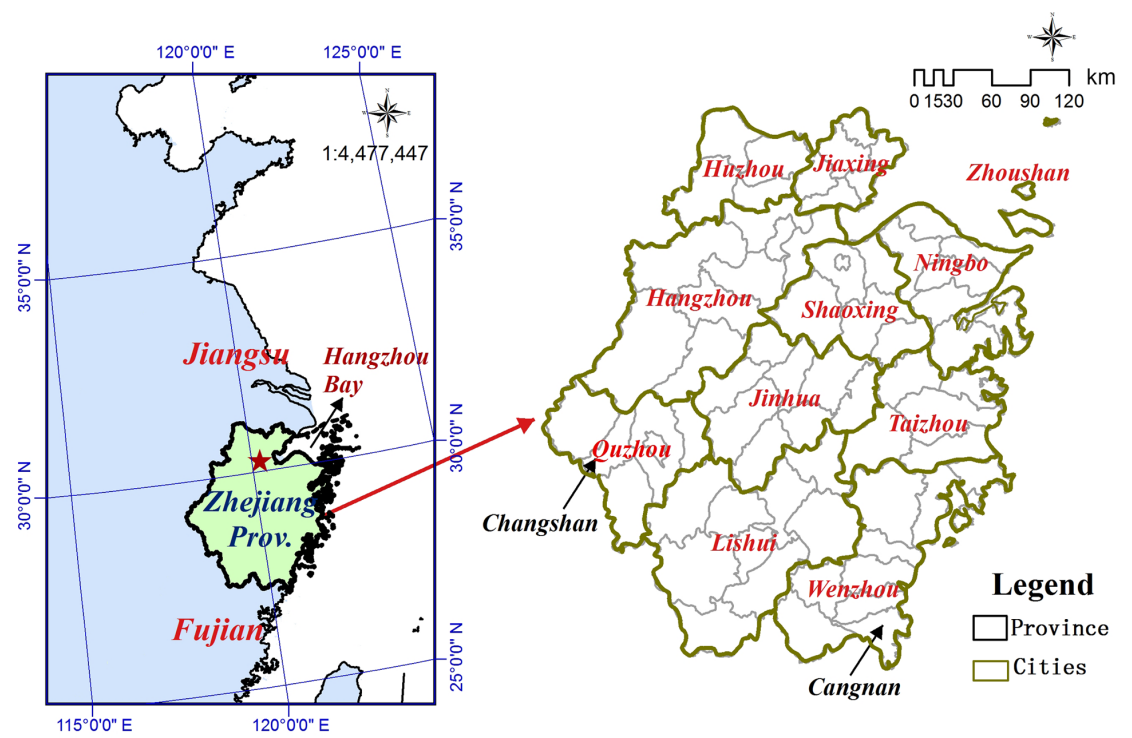

Figure 1. Maps of Zhejiang Province, China, showing location and major cities.

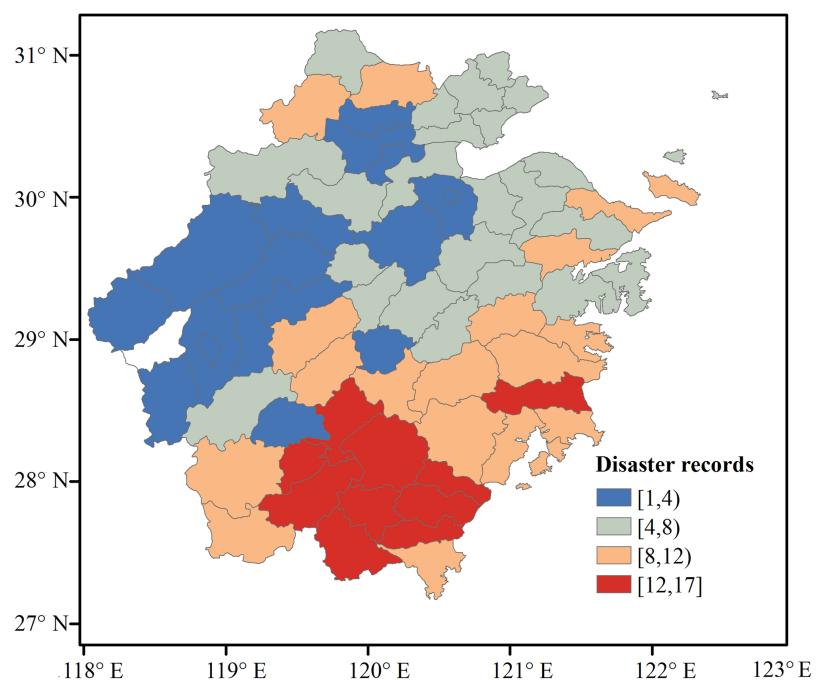

Figure 2. Number of records of typhoon disasters in Zhejiang Province from 2004 to 2012.

National Bureau of Statistics of China) and the 2010 statistical yearbooks of each city in Zhejiang Province published by the cities' statistical bureaus. The census data are updated every 6 years, and the 2010 census results coincide with the period of 2004-2012, which is the research period. Therefore, the population data for 2010 in this paper can basically represent the population vulnerability of this period. Basic geographical data are obtained from the National Geomatics Center of China.

\subsection{Methods}

\subsubsection{Objective synoptic analysis technique}

The widely used the OSAT proposed by Ren et al. (2001, 2007) and Ren and Wu (2011) is used to identify precipitation due to typhoons in this study. The OSAT is a numerical technique to separate tropical-cyclone-induced precipitation from adjacent precipitation areas. Based on structural analysis of precipitation fields, it can be divided into different rain belts. Then, according to the distances between a typhoon center and these rain belts and the typhoon center and each station, typhoon precipitation is distinguished. $\mathrm{Lu}$ et al. (2016) improved the OSAT and applied it to identify typhoon winds. With the application of the OSAT method, daily precipitation and wind data over the mainland of China from 1980 to 2014 are used for identifying typhoon precipitation and wind data.

\subsubsection{Canonical correlation analysis (CCA)}

We use the canonical correlation analysis method (CCA) to determine the relationship among the affected population, the rate of economic damage, and typhoon precipitation and winds. In statistics, CCA is a way of inferring information from cross-covariance matrices. If we have two vectors $X=$ $\left(\boldsymbol{X}_{1}, \ldots, \boldsymbol{X}_{n}\right)$ and $\boldsymbol{Y}=\left(\boldsymbol{Y}_{1}, \ldots, \boldsymbol{Y}_{m}\right)$ of random variables, and there are correlations among the variables, then CCA can find linear combinations of $X_{i}$ and $Y_{j}$, which have a maximum correlation with each other (Hardoon et al., 2014). The method was first introduced by Hotelling in 1936 (Hotelling, 1936). The main point of CCA is to separate linear combinations of new variables from the two sets of variables. In this 

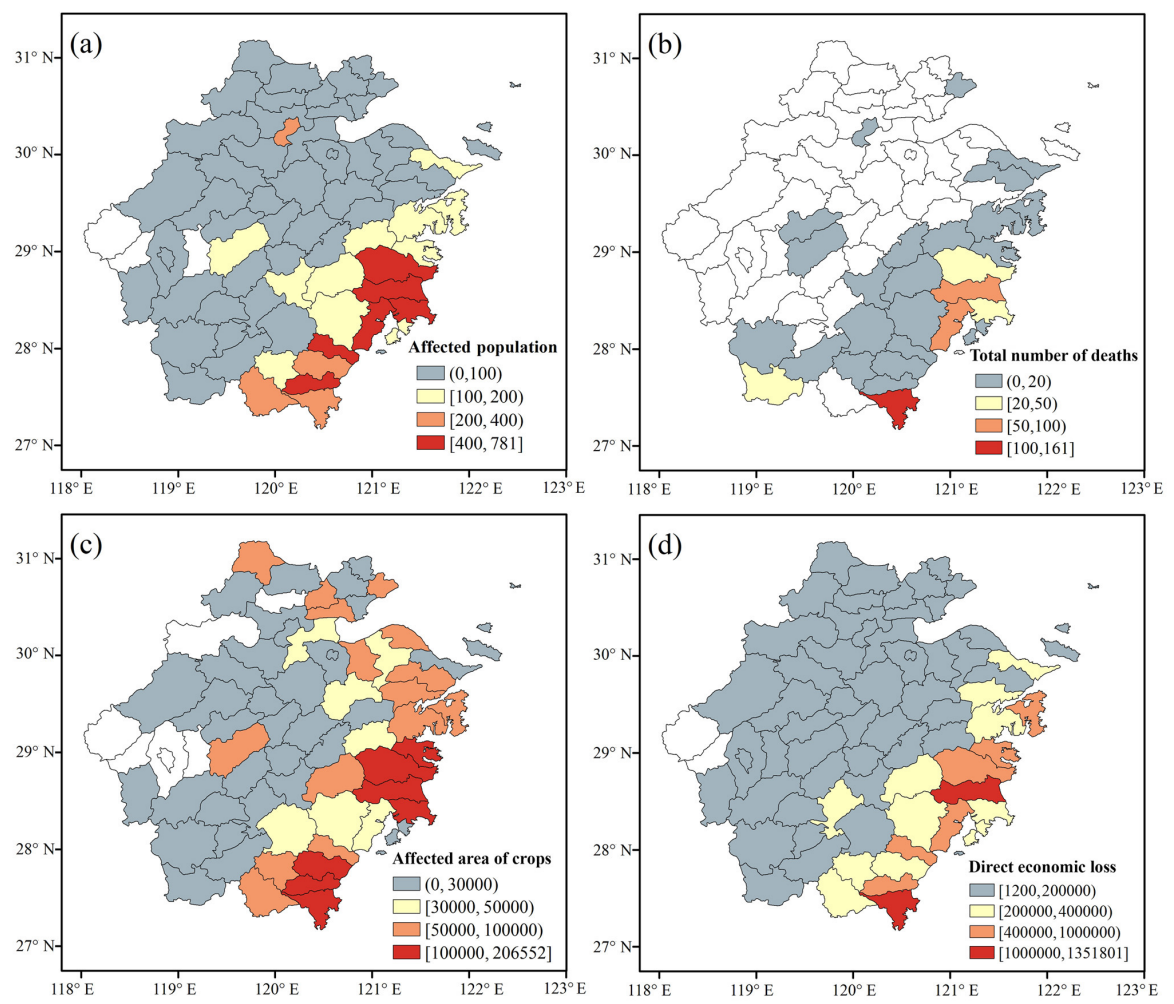

Figure 3. Distribution of typhoon disaster losses in Zhejiang Province from 2004 to 2012. (a) Affected population (millions), (b) total number of deaths (person), (c) area of affected crops (hectares) and (d) direct economic losses (millions of yuan).

case, the correlation coefficient among new variables reaches the maximum. In this paper, we chose factors causing typhoon disasters as a set of variables and typhoon disaster as another. Under the maximum canonical correlation coefficient, the linear combination coefficients (typical variable coefficients) of factors causing typhoon disasters can be used as weight coefficients of this group of variables. Then we can determine the impact of factors causing typhoon disasters.

\subsubsection{Data standardization}

We adopt two methods: $Z$-score standardization and minmax standardization. The $Z$-score standardized method is based on the mean and standard deviation of the raw data, which is the precondition for the CCA method. The min-max standardization is a linear transformation of the original data so that the original value maps the interval $[0,1]$. $Z$-score standardization is used for calculating the intensity index of factors causing typhoon disasters. Both typhoon precipitation and typhoon maximum wind speed are standardized by this method. When calculating the comprehensive typhoon disaster risk index $(R)$, we use min-max standardization to standardize the intensity index of the factors causing typhoon disasters $(I)$ and the population vulnerability index (SoVI).

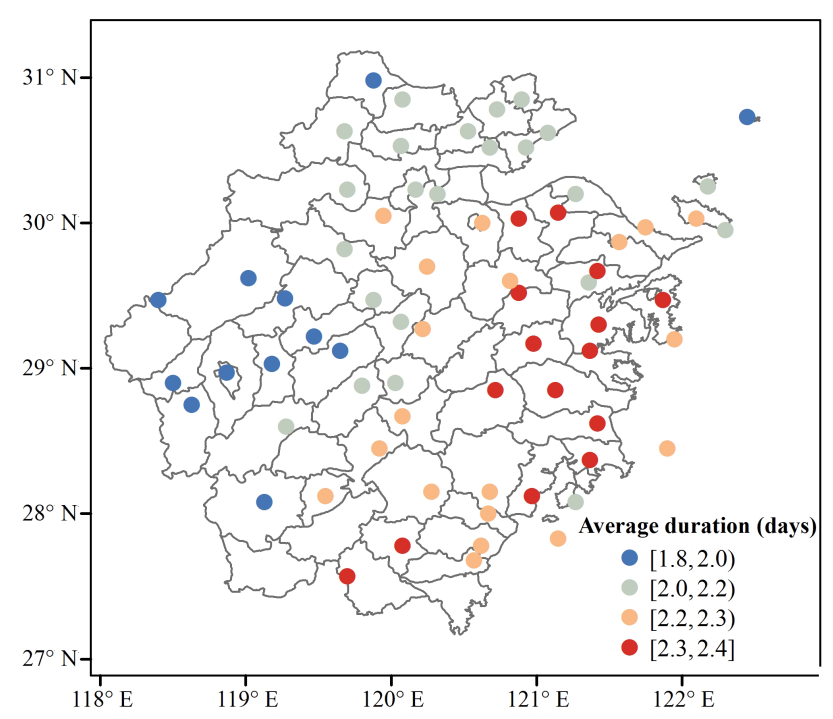

Figure 4. Average duration (days) of typhoon precipitation at each station in Zhejiang Province from 1980 to 2014.

\subsubsection{Vulnerability assessment (SoVI, PCA)}

County-level socioeconomic and demographic data are used to construct an index of social vulnerability to environmen- 


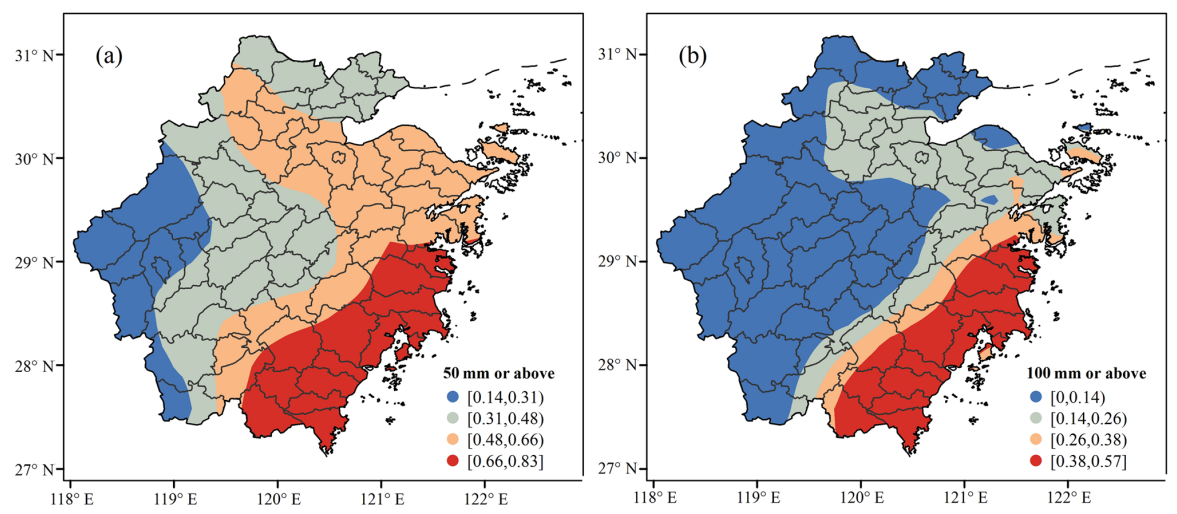

Figure 5. Probability of the occurrence of typhoon rainstorms in Zhejiang Province: (a) rainstorms with precipitation $>50 \mathrm{~mm}$ and (b) torrential rainstorms with precipitation $>100 \mathrm{~mm}$.

tal hazards named the SoVI. Principal component analysis (PCA) is the primary statistical technique for constructing the SoVI. The PCA method captures multidimensionality by transforming the raw dataset to a new set of independent variables. Then a few components can represent the dimensional data, and underlying factors can be identified easily. These new factors are placed in an additive model to compute a summary score - SoVI (Cutter et al., 2003). Based on various SoVIs derived for disaster social vulnerability in America, Chen et al. (2014) collects 29 variables as proxies to build a set of vulnerability indexes for the social and economic environment in China. We then use these vulnerability indexes to calculate the population vulnerability index for Zhejiang Province.

\section{Typhoon disaster losses and factors}

Based on the distribution of typhoon disaster losses in Zhejiang Province from 2004 to 2012 (Fig. 3), the affected areas are mainly located in the southeast corner of the province. The centers with the largest affected population (Fig. 3a), the largest area of affected crops (Fig. 3c) and the highest direct economic losses (Fig. 3d) are in Wenzhou and Taizhou cities, although the losses in Ningbo City are also relatively high. Cangnan in Wenzhou City is the most severely affected, with the highest cumulative death toll (Fig. 3b). According to the statistical yearbooks of each city in Zhejiang Province, Jiaxing, Shaoxing, Hangzhou in the northeast, and Wenzhou, Jinhua and Taizhou in the southwest are the regions with the largest agricultural planting area, with more agricultural population in the southwest. Only parts of the plain area were affected by serious agricultural disasters in the northeast. The agricultural disaster areas in the southwest are wider (Fig. 3c). According to the main indicators of Zhejiang's national economy (total GDP and per capita GDP), central cities such as Hangzhou in the northeast had the most developed economy, and the urban economies of

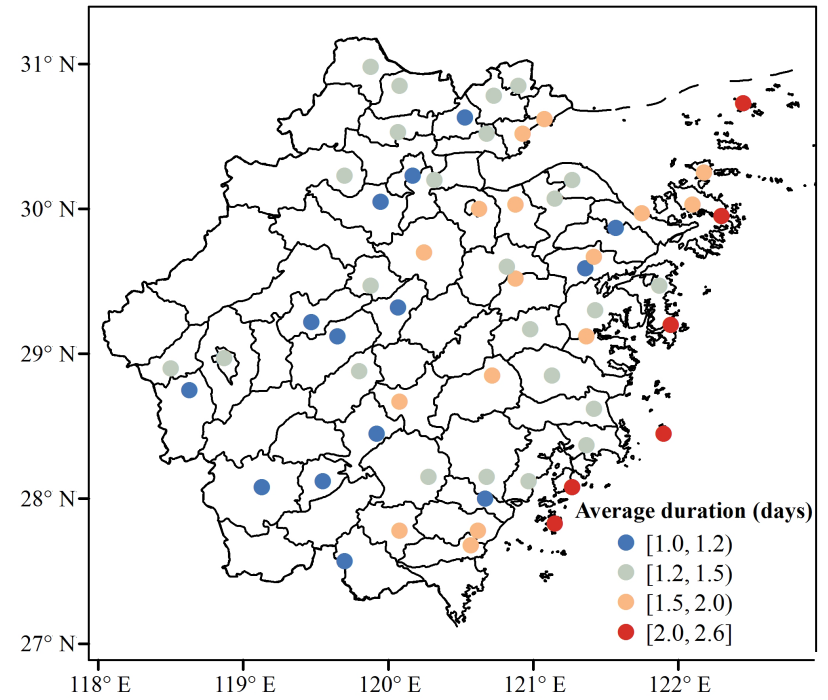

Figure 6. Average duration (days) of typhoon winds (over grade 6) at each station in Zhejiang Province from 1980 to 2014.

Wenzhou and Taizhou in the southwest were also relatively good. However, the economic losses in southwestern Zhejiang are severe, much higher than in the northeastern cities (Fig. 3d). The losses in the affected counties are associated with the frequency and intensity of typhoons. We therefore analyze the risk of typhoon precipitation and winds in every county in Zhejiang Province to provide a reference dataset for the factors causing typhoon disasters.

\subsection{Probability of typhoon rainstorms}

The main hazard of typhoon precipitation is concentrated precipitation, so the average duration (days) of typhoon precipitation at each station in Zhejiang Province is counted from 1980 to 2014 (Fig. 4). The duration of typhoon rainfall is less in inland areas, especially in Quzhou City. Persis- 

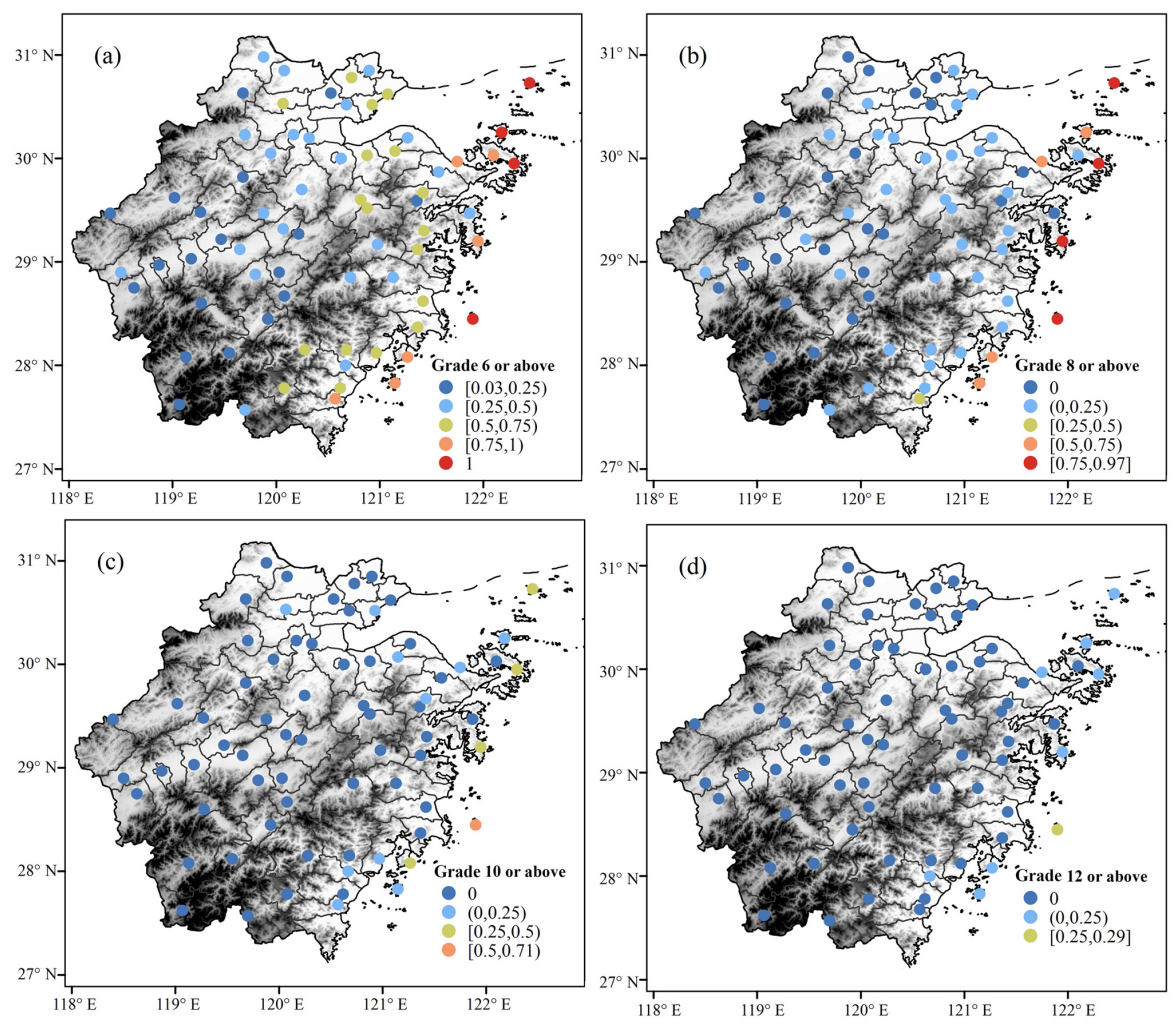

Figure 7. Probability of the occurrence of typhoon winds in Zhejiang Province at (a) grade 6 or above $\left(\geq 10.8 \mathrm{~m} \mathrm{~s}^{-1}\right)$, (b) grade 8 or above $\left(\geq 24.5 \mathrm{~m} \mathrm{~s}^{-1}\right)$, (c) grade 10 or above $\left(\geq 32.7 \mathrm{~m} \mathrm{~s}^{-1}\right)$ and (d) grade 12 or above $\left(\geq 41.5 \mathrm{~m} \mathrm{~s}^{-1}\right)$.

tent precipitation is concentrated in Wenzhou, Taizhou and Ningbo cities, where there may have been a higher risk of typhoon disasters. Typhoon rainstorm in this study means daily typhoon precipitation over $50 \mathrm{~mm}$, and typhoon torrential rainstorm means daily typhoon precipitation over $100 \mathrm{~mm}$. The probability is the annual possibility of the occurrence of typhoon rainstorms. The probability denominator is the total number of years, and the numerator is the annual frequency of typhoon precipitation. If a station experiences typhoon precipitation in 1 year, the numerator increases by 1 . Based on the probability of typhoon rainstorms occurring in each county in Zhejiang Province (Fig. 5), we found that the annual probability of the occurrence of typhoon rainstorms is highest over the southeast coast of Zhejiang Province from 1980 to 2014, especially in Taizhou City, where the annual probability is $83 \%$. The annual probability of typhoon rainstorms with precipitation $>100 \mathrm{~mm}$ is lower, but the distribution of probability is consistent with the rainstorms with lower precipitation. The probability of typhoon torrential rainstorms decreases rapidly in the western and central regions of Zhejiang Province, although the range increases. There are three centers of high probability: Taizhou, Wenzhou and Ningbo cities.

\subsection{Probability of typhoon winds}

The average duration (days) of typhoon winds (over grade 6) is calculated in Zhejiang Province (Fig. 6). The duration of typhoon winds is relatively short in the central and western regions and the typhoon winds are concentrated in the coastal areas of Wenzhou, Taizhou and Ningbo cities. The longest duration of typhoon winds occurs over the offshore islands.

The main hazard from typhoon winds is manifested in the destructive force of strong winds. Therefore, we calculate the probability of annual occurrence of typhoon winds at or above grades 6 and 12 at each station from 1980 to 2014 (Fig. 7). Typhoon winds at or above grade 6 mainly occur along the coastal areas, with a rare occurrence in the mountainous areas. Meanwhile, the probability of typhoon winds at or above grade 8 is generally $0.5-0.9$ along the coast and below 0.25 in the inland mountainous areas. Typhoon winds at or above grade 10 or 12 are much less likely and are only seen around the coastal areas and islands, with a rapidly decreasing probability from the coastal areas to the inland mountainous areas. The areas with a high probability of typhoon winds are consistent with those with a high probability of typhoon rain, i.e., Wenzhou, Taizhou and Ningbo cities. The probability of typhoon extreme winds is much higher in coastal areas than inland. 


\section{Risk assessment and regionalization of typhoon disasters}

\subsection{Intensity index of factors causing typhoon disasters}

The main factors causing typhoon disasters, which are considered in this study, are rainstorms and winds. The level and intensity of a single factor cannot fully represent and describe the impact. It is necessary to determine their influence through typical correlation analysis, and then typhoon wind and rain effect are superimposed by the weight coefficients. Therefore, we establish a comprehensive intensity index that includes typhoon precipitation and winds. Taking the county as a unit, we select all the typhoons that affected the population of Zhejiang Province from 2004 to 2012. The total precipitation and daily maximum wind speed during typhoons measured in each county are used to describe the factors causing typhoon disasters. The total sample size is 322 . Using CCA, we determine the impact of typhoon precipitation and winds on the population. We then perform CCA for all the typhoons that caused direct economic losses in Zhejiang Province from 2004 to 2012, and the total sample size is 404 (Table 1). The effect of typhoon precipitation on both the population and direct economic losses is always greater than that of typhoon winds. By averaging typical coefficients for both precipitation and wind, weight coefficients of 0.85 and 0.65 are obtained within the intensity index for precipitation and winds, respectively.

Based on the weight coefficients in Table 1, an intensity index of factors causing typhoon disasters is established:

$I=A x+B y$,

where $I$ is the intensity index of factors causing typhoon disasters, $X$ is the standard typhoon precipitation and $Y$ is the maximum wind speed of the typhoon. $A$ and $B$ are the weight coefficients for typhoon precipitation and typhoon winds, respectively. Using Eq. (1), we average the intensity indexes of typhoons at each station (Fig. 8). Based on the distribution of these average intensity indexes, three high-value centers, namely Wenzhou, Taizhou and Ningbo cities are identified, which is consistent with the results of $\mathrm{H}$. Y. Chen et al. (2011).

\subsection{Population vulnerability index}

Natural disasters are social constructions and the basic causes of losses are the attributes of human beings and their social system (Jiang, 2014). The index system of W. F. Chen et al. (2011) is used to evaluate the vulnerability of Zhejiang Province. Based on the extracted population information, 29 variables are identified that may affect vulnerability (Table 2).

After PCA of the 29 variables, seven components with an eigenvalue $>1$ are extracted. Based on the variable meanings in each component, these seven components are named in Ta-

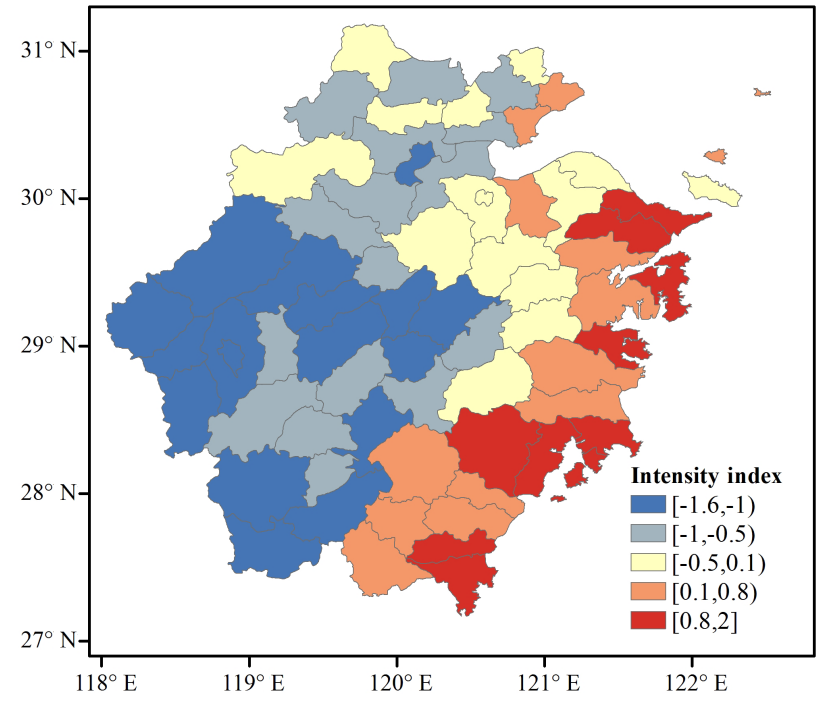

Figure 8. Intensity indexes of factors causing typhoon disasters at each station in Zhejiang Province.

ble 3. The first component, which reflects the income of the population and the employment situation, contributes $30.1 \%$ of the total variance. This component is positive because the more property there is in an area, the higher the vulnerability to damage. The second component, which reflects education level of the population, occupies $15.6 \%$ of the total variance. This component is negative because if education level is higher, then the population's awareness of disaster prevention and reduction is greater and their vulnerability is lower. The third component, which reflects the number of dilapidated houses, takes up $8.7 \%$ of the total variance. This component plays a positive part in vulnerability. The fourth component, which reflects the illiteracy and the number of young people, is positive and represents $8.4 \%$ of the total variance. The fifth component, which reflects the household size and the percentage of women, explains $7.7 \%$ of the total variance and is positive. The sixth component, which reflects the number of ethnic minorities, contributes $6.1 \%$ of the total variance and is positive. The seventh component, which represents $5.3 \%$ of the total variance, reflects the unemployment rate and the housing area and is positive.

The total variance explained by these seven components is up to $81.9 \%$, which can be used to represent the population vulnerability of Zhejiang Province. The distributions of the first (positive) component and the second (negative) component are shown in Fig. 9. Areas with a low employment rate have high vulnerability, but the vulnerability is low in urban areas with higher levels of education. The seven components thus represent the real vulnerability of the population in Zhejiang Province to the effect of typhoons. The population vulnerability index in Zhejiang Province (SoVI) is calculated as 
Table 1. Canonical correlation analysis of factors causing typhoon disasters.

\begin{tabular}{lrrr}
\hline \multirow{2}{*}{ Disasters } & Canonical correlation & Canonical variable coefficient \\
\cline { 3 - 4 } & coefficient & $\begin{array}{r}\text { Typhoon } \\
\text { precipitation }\end{array}$ & $\begin{array}{r}\text { Typhoon } \\
\text { wind }\end{array}$ \\
\hline Affected population & 0.45 & 0.84 & 0.651 \\
Direct economic losses & 0.477 & 0.863 & 0.655 \\
\hline
\end{tabular}
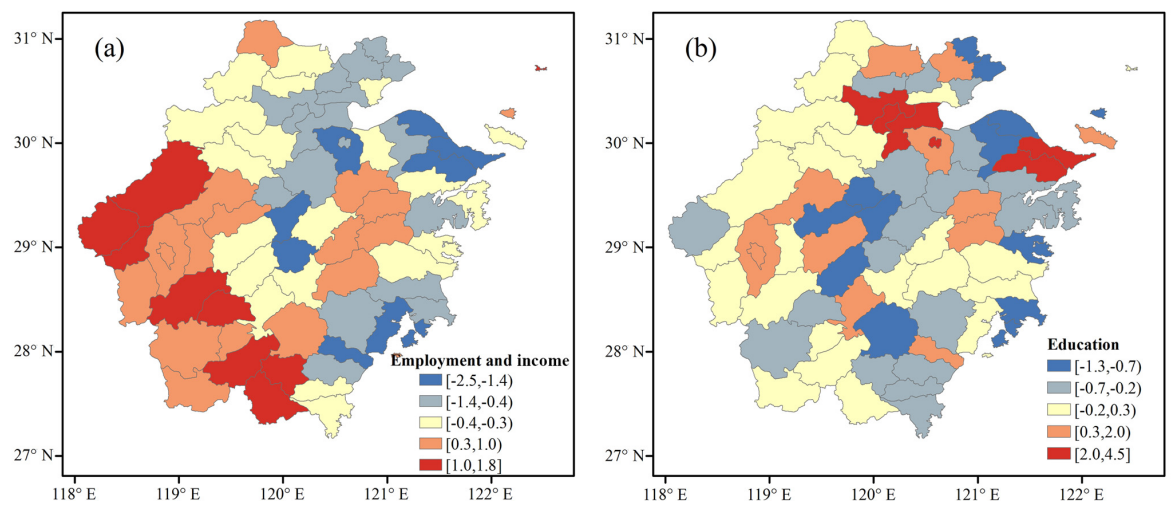

Figure 9. Distribution of population vulnerability index of (a) component 1 (employment and income) and (b) component 2 (education).

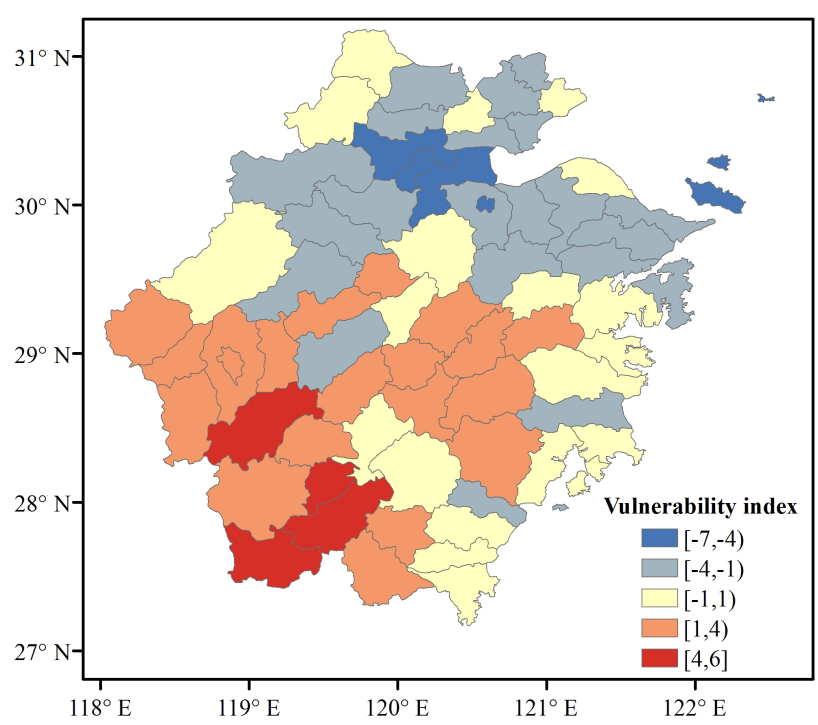

Figure 10. Distribution of population vulnerability index of counties.

SoVI $=$ component $1-$ component $2+$ component 3

+ component $4+$ component $5+$ component 6

+ component 7 .

By calculating the vulnerability indexes of each county, the distribution of population vulnerability in Zhejiang Province is obtained (Fig. 10). The areas with high vulnerabilities are mountainous regions where the economy is relatively undeveloped, whereas the vulnerability is low in cities, such as Hangzhou and Huzhou cities, where there is a greater awareness of disaster prevention and reduction and houses are of high quality.

\subsection{Comprehensive typhoon disaster risk index and zoning}

The typhoon disaster risk assessment system is mainly composed of the factors causing disasters, the population vulnerability and the environment. In this paper, comprehensive typhoon disaster risk index is obtained by combining the factors causing typhoon disasters and vulnerability, without taking the sensitivity of the environment into account. After standardizing the intensity index of factors causing typhoon disasters and the population vulnerability index, the comprehensive typhoon disaster risk index $(R)$ is obtained as follows:

$\begin{aligned} R= & \text { intensity index of factors causing typhoon disasters }(I) \\ & \times \text { vulnerability index (SoVI). }\end{aligned}$

Based on the comprehensive risk index, five risk grades for typhoon disasters are defined (Table 4), and risk zoning of typhoon disasters in Zhejiang Province has been carried out as shown in Fig. 11. The classification of typhoon disaster risk index is based on the natural breaks method provided by ArcGIS. 
Table 2. The 29 variables affecting vulnerability in Zhejiang Province.

\begin{tabular}{|c|c|c|}
\hline & Variables & Name \\
\hline 1 & Per capita disposable income of urban residents (yuan) & UBINCM \\
\hline 2 & Percentage of females $(\%)$ & QFEMALE \\
\hline 3 & Percentage of minorities (\%) & QMINOR \\
\hline 4 & Median age & MEDAGE \\
\hline 5 & $\begin{array}{l}\text { Unemployment rate (calculated - unemployed popula- } \\
\text { tion/(unemployed + total population) }\end{array}$ & QUNEMP \\
\hline 6 & Population density & POPDEN \\
\hline 7 & Percentage of urban population $(\%)$ & QUBRESD \\
\hline 8 & $\begin{array}{l}\text { Percentage of nonagricultural household population } \\
(\%)\end{array}$ & QNONAGRI \\
\hline 9 & Percentage of households that live in rented houses (\%) & QRENT \\
\hline 10 & $\begin{array}{l}\text { Percentage of employees working in primary industries } \\
\text { and mining }(\%)\end{array}$ & QAGREMP \\
\hline 11 & $\begin{array}{l}\text { Percentage of employees working in secondary indus- } \\
\text { tries }(\%)\end{array}$ & QMANFEMP \\
\hline 12 & $\begin{array}{l}\text { Percentage of employees working in tertiary industries } \\
(\%)\end{array}$ & QSEVEMP \\
\hline 13 & Household size (people per household) & PPUNIT \\
\hline 14 & $\begin{array}{l}\text { Percentage of population with a college degree ( } 25 \\
\text { years old and older) }\end{array}$ & QCOLLEGE \\
\hline 15 & $\begin{array}{l}\text { Percentage of population with a high school diploma } \\
\text { ( } 20 \text { years old and older) }\end{array}$ & QHISCH \\
\hline 16 & Percentage of illiterate people ( 15 years old and older) & QILLIT \\
\hline 17 & Population growth rate (2000-2010) & POPCH \\
\hline 18 & $\begin{array}{l}\text { Average number of rooms per household } \\
\text { (rooms per household) }\end{array}$ & PHROOM \\
\hline 19 & Per capita housing construction area $\left(\mathrm{m}^{2}\right.$ per person $)$ & PPHAREA \\
\hline 20 & Percentage of premises without tap water (\%) & QNOPIPWT \\
\hline 21 & Percentage of premises without a kitchen $(\%)$ & QNOKITCH \\
\hline 22 & Percentage of premises without a toilet $(\%)$ & QNOTOILET \\
\hline 23 & Percentage of premises without a bath $(\%)$ & QNOBATH \\
\hline 24 & $\begin{array}{l}\text { Number of beds per } 1000 \text { people in health care institu- } \\
\text { tions }\end{array}$ & HPBED \\
\hline 25 & Number of medical personnel per 1000 people & MEDPROF \\
\hline 26 & Percentage of people under 5 years old & QPOPUD5 \\
\hline 27 & Percentage of population over 65 years old & QPOPAB65 \\
\hline 28 & Population dependency ratio (\%) & QDEPEND \\
\hline 29 & $\begin{array}{l}\text { Percentage of population covered by subsistence } \\
\text { allowances }(\%)\end{array}$ & QSUBSIST \\
\hline
\end{tabular}


Table 3. The seven components extracted by PCA.

\begin{tabular}{llll}
\hline Components & Contained variables & Name & $($ Sign) \\
\hline 1 & QMANFEMP, UBINCM, QAGREMP, & Employment and poverty & $(+)$ \\
& QRENT, POPCH, QDEPEND, \\
& QSUBSIST, QPOPAB65, POPDEN, & & \\
& MEDAGE, QNOKITCH, QILLIT, & & \\
& PHROOM, PPHAREA & $(-)$ \\
\hline 2 & QHISCH, QCOLLEGE, QNONAGRI, & Education & $(+)$ \\
\hline 3 & QSEVEMP, HPBED, MEDTECH & & $(+)$ \\
\hline 4 & QNOBATH, QNOTOILET, PPUNIT & Number of dilapidated houses & \\
\hline 5 & QILLIT, QDEPEND, QPOPUD5, & Illiteracy and juvenile population & $(+)$ \\
& MEDAGE & & $(+)$ \\
\hline 7 & QFEMALE, PHROOM, PPHAREA, & Household size and ratio of women & $(+1$ \\
\hline
\end{tabular}

Table 4. Disaster risk index and grading.

\begin{tabular}{lrrrrr}
\hline Risk grade: & High & High-medium & Medium & Medium-low & Low \\
\hline Risk index: & 0.3 & $0.18-0.3$ & $0.13-0.18$ & $0.07-0.13$ & 0.07 \\
\hline
\end{tabular}

Figure 11 shows that the index presents a good reflection of the distribution of typhoon disasters in Zhejiang Province (Fig. 3), especially in the southeastern coastal areas. The southeastern coastal areas face the highest risk, especially in the boundary regions between Zhejiang and Fujian provinces, and Taizhou and Wenzhou cities. Overall, the risk of typhoon disasters decreases from the coast to inland areas. Cities are at medium to low risk as a result of their developed economy, high-quality houses and better-educated population. The inland mountainous areas have a high vulnerability. Although they are not directly affected by typhoons, they are still in the middle risk areas as a result of their poorly developed economy.

\section{Discussion and conclusions}

1. An intensity index of factors causing typhoon disasters is developed, with the highest values in Wenzhou, Taizhou and Ningbo cities. A comparison between the distributions of the intensity index and actual typhoon disasters in Zhejiang Province from 2004 to 2012 shows that the index is a good reflection of the possibility of typhoon disasters.

2. Seven components are extracted after PCA of 29 variables affecting vulnerability. These seven factors represent $81.9 \%$ of the total variance and are a good reflec-

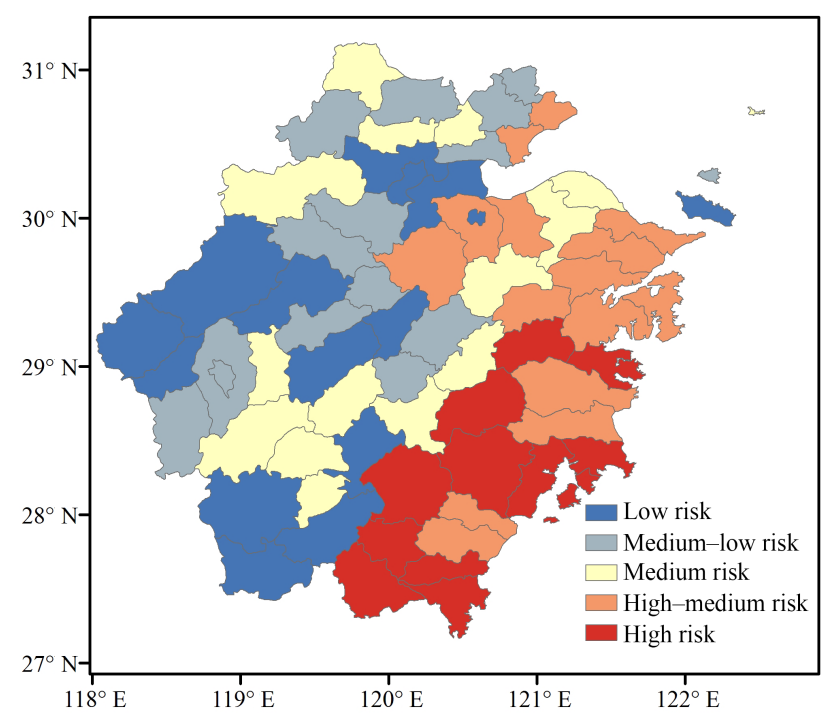

Figure 11. Risk zoning of typhoon disasters in Zhejiang Province.

tion of the index of population vulnerability in Zhejiang Province. Southwestern Zhejiang is the most vulnerable as it has a relatively undeveloped economy, more mountainous areas and a higher risk of geological disasters. Vulnerabilities are lower in cities as a result of 
better disaster prevention and reduction measures and a better-educated population.

3. The comprehensive typhoon disaster risk index is obtained by combining the factors causing typhoon disasters and population vulnerability. Based on the comprehensive risk index, risk zoning of typhoon disasters in Zhejiang Province is achieved. The southeastern coastal areas are at high risk, especially the boundary regions between Zhejiang and Fujian provinces and Taizhou and Wenzhou cities. The risk of typhoon disasters decreases quickly from coastal areas to inland regions. Cities are at medium to low risk because of their developed economy, high-quality houses and better-educated population.

4. Although some interesting results have been obtained in this study, there are still some problems that require further study. As a result of the limited data on typhoon disasters, it is currently impossible to give a long time trend for high-resolution typhoon disaster analysis. It is also unclear whether this methodology can be applied to other regions. This paper mainly considers the effects of typhoon rain and typhoon wind, without considering the impact of storm surge. This is the limitation of the study, and we will explore the role of storm surges in future work.

Data availability. The typhoon data used in this study are the best-track tropical cyclone datasets from Shanghai Typhoon Institute, which can be obtained from http://tcdata.typhoon.org.cn/ zjljsjj_zlhq.html (last access: November 2018). Daily precipitation data and daily wind data during the time period 1960-2014 over the mainland of China are obtained from the National Meteorological Information Center. Due to the data privacy policy of research institutions, these data are not publicly available. Disaster data for each typhoon that affected Zhejiang Province from 2004 to 2012 are obtained from the National Climate Center; because of the data privacy policy of research institutions, these data are also not public. The population data in 2010 are obtained from the sixth national population census, which can be obtained from http://www.stats.gov.cn/tjsj/pcsj/rkpc/6rp/indexch.htm (last access: November 2018). The 2010 statistical yearbooks of each city in Zhejiang Province are from http://tjj.zj.gov.cn/col/col1525563/ index.html (last access: November 2018), which are published by the cities' statistical bureaus.

Author contributions. All co-authors took part in the research. While FR mainly conceived the idea, YL mainly developed the study methods and performed the calculations. YL prepared the paper with contributions from all the co-authors.

Competing interests. The authors declare that they have no conflict of interest.
Acknowledgements. This study is supported by the National Basic Research Program of China (grant no. 2015CB452806), Shanghai Meteorological Bureau of Science and Technology Development Project (grant no. QM201801), and fundamental research funds of the Shanghai Typhoon Institute of the China Meteorological Administration (grant no. 2018JB05).

Edited by: Maria Ana Baptista

Reviewed by: Charles Guard and four anonymous referees

\section{References}

Chen, H. Y., Yan, L. N., and Lou, W. P.: On assessment indexes of the strength of comprehensive impacts of tropical cyclone disaster-causing factors, J. Trop. Meteorol., 27, 139-144, 2011 (in Chinese).

Chen, W. F., Xu, W., and Shi, P. J.: Risk assessment of typhoon disaster at county level in the Yangtze river delta of China, Journal of Natural Disasters, 4, 77-83, 2011.

Chen, W. F., Duan, Y. H., and Lu, Y.: Review on Tropical Cyclone Risk Assessment, Journal of Catastrophology, 32, 146-152, 2017 (in Chinese).

Chen, X.: Vulnerability diagnosis and assessment of typhoon disaster system at coastal regions, a case study of Fujian province, Journal of Catastrophology, 22, 6-10, 2007 (in Chinese).

Cutter, S. L., Boruff, B. J., and Shirley, W. L.: Social Vulnerability to Environmental Hazards, Soc. Sci. Quart., 84, 242-261, 2003.

Ding, Y. and Shi, P. J.: Fuzzy risk assessment model of typhoon hazard, Journal of Natural Disasters, 11, 34-43, 2002 (in Chinese).

Emanuel, K. A.: The maximum intensity of hurricanes, J. Atmos. Sci., 45, 1143-1155, 1988.

Emanuel, K. A.: The dependence of hurricane intensity on climate, American Institute of Physics, 277, 25-33, 1992.

Emanuel, K. A.: Sensitivity of tropical cyclones to surface exchange coefficients and a revised steady-state model incorporating eye dynamics, J. Atmos. Sci., 52, 3969-3976, 1995.

Eunjeong, C. and Ying, M.: Comparison of three western North Pacific tropical cyclone best track datasets in seasonal context, J. Meteorol. Soc. Japan, 89, 211-224, 2009.

Fang, W. H. and Lin, W.: A review on typhoon wind field modeling for disaster risk assessment, Prog. Geogr., 32, 852-867, 2013 (in Chinese).

Fang, W. H. and Shi, X. W.: A review of stochastic modeling of tropical cyclone track and intensity for disaster risk assessment, Adv. Earth Sci., 27, 866-875, 2012 (in Chinese).

Friedman, D. G.: Natural hazard risk assessment for an insurance program, The Geneva Papers on Risk and Insurance - Issues and Practice, 9, 57-128, 1984.

Hardoon, D. R., Szedmak, S., and Shawetaylor, J.: Canonical Correlation Analysis: An Overview with Application to Learning Methods, Neural Computation, 16, 2639-2664, 2014.

Hendrick, R. L. and Friedman, D. G.: Potential impacts of storm modification on the insurance industry, University of Chicago Press, Chicago, 227-248, 1966.

Holland, G. J.: The maximum potential intensity of tropical cyclones, J. Atmos. Sci., 54, 2519-2541, 1997.

Hotelling, H.: Relations between two sets of variates, Biometrika, 28, 321-377, 1936. 
Howard, R. A., Matheson, J. E., and North, D. W.: The decision to seed hurricanes, Science, 176, 1191-1202, 1972.

Huang, W. K. and Wang, J. J.: Typhoon damage assessment model and analysis in Taiwan, Nat. Hazards, 79, 497-510, 2015.

Jiang, T., Li, X. C., and Chao, Q. C.: Highlights and understanding of climate change 2014: impacts, adaptation, and vulnerability, Advances in Climate Change Research, 10, 157-166, 2014.

Kafali, C. and Jain, V.: A Methodology for Estimating Typhoon Losses to Building Environment in Japan, in: Proceedings of the 11th Americas Conference on Wind Engineering, San Juan, Puerto Rico, 2009.

Kunreuther, H. and Roth, R. J.: The Status and Role of Insurance Against Natural Disaster in the United States, Washington Joseph Henry Press, 1998.

Lei, X. T., Chen, P. Y., Yang, Y. H., and Qian, Y. Z.: Characters and objective assessment of disasters caused by typhoons in china, Acta Meteorologica Sinica, 67, 875-883, 2009 (in Chinese).

Li, S. H. and Hong, H. P.: Use of historical best track data to estimate typhoon wind hazard at selected sites in China, Nat. Hazards, 76, 1395-1414, 2015.

Liang, B. Q. and Fan, Q.: A fuzzy mathematic of the disaster bytropical cyclones, J. Trop. Meteorol., 4, 305-311, 1999 (in Chinese).

Liu, T. J. and Gu, J. Q.: A statistical analysis of typhoon disasters in Zhejiang province, Journal of Catastrophology, 17, 64-71, 2002 (in Chinese).

Lu, Y., Zhu, W. J., Ren, F. M., and Wang, X.: Changes of Tropical Cyclone High Winds and Extreme Winds During 1980-2014 over China, Advances in Climate Change Research, 12, 413-421, 2016 (in Chinese).

Niu, H. Y., Liu, M., and Lu, M.: Risk assessment of typhoon disasters in china coastal area during last 20 years, Scientia Geographica Sinica, 31, 764-768, 2011 (in Chinese).

Pielke, R. A. J. and Landsea, C. W.: Normalized hurricane damages in the United States: 1925-95, Weather Forecast., 13, 621-631, 1998.

Pielke, R. A. J., Gratz, J., and Landsea, C. W.: Normalized hurricane damage in the United States: 1900-2005, Nat. Hazards Rev., 9, 29-42, 2008.
Pita, G., Pinelli, J. P., and Gurley, K.: State of the art of hurricane vulnerability estimation methods: a review, Nat. Hazards Rev., 16, 04014022, https://doi.org/10.1061/(ASCE)NH.15276996.0000153, 2014.

Ren, F. M. and Wu, G. X.: Tropical cyclone over the past 60 years, China Meteorological Press, Beijing, 2011 (in Chinese).

Ren, F. M., Byron, G., and David, E.: A Numerical Technique for Partitioning Cyclone Tropical Precipitation, J. Trop. Meteorol., 17, 308-313, 2001 (in Chinese).

Ren, F. M., Wang, Y., Wang, X., and Li, W.: Estimating Tropical Cyclone Precipitation from Station Observations, Adv. Atmos. Sci., 24, 700-711, 2007.

Ren, F. M., Wang, X. L., Chen, L. S., and Wang, Y. M.: Tropical cyclones landfalling on mainland China, Hainan and Taiwan and their correlations, Acta Meteorologica Sinica, 66, 224-235, 2008 (in Chinese).

Su, G. L., Miao, C. M., and Mao, Y. D.: Typhoon hazard in zhejiang province and risk assessment of its influence on agriculture, Journal of Natural Disasters, 17, 113-119, 2008 (in Chinese).

Vickery, P. J., Masters, F. J., and Powell, M. D.: Hurricane hazard modeling: the past, present, and future, Journal of Wind Engineering \& Industrial Aerodynamics, 97, 392-405, 2009.

Wang, X. R., Wang, W. G., and Ma, Q. Y.: Model for general grade division of typhoon disasters and application, Meteorol. Mon., 36, 66-71, 2010 (in Chinese).

$\mathrm{Xu}, \mathrm{X}$., Sun, D., and Guo, T.: A systemic analysis of typhoon risk across china, Nat. Hazards, 77, 461-477, 2015.

Yin, Y. Z. and Li, H. L.: Preliminary study on pre-evaluation method of typhoon disaster in China, Meteorol. Mon., 43, 716-723, 2017 (in Chinese).

Yin, Z. E., Xu, S. Y., Yin, J., and Wang, J.: Small-scale Based Scenario Modeling and Disaster Risk Assessment of Urban Rainstorm Water-logging, Acta Geographica Sinica, 65, 553-562, 2010 (in Chinese).

Zhang, Q., Wu, L. G., and Liu, Q. F.: Tropical cyclone damages in china 1983-2006, B. Am. Meteorol. Soc., 90, 489-495, 2009. 